\title{
SÍMBOLOS DE PODER: UN ANÁLISIS COMPARATIVO ENTRE LA ICONOGRAFÍA DEL CLÁSICO MAYA Y LOS CÓDICES MIXTECOS
}

\author{
Manuel A. Hermann Lejarazu \\ Centro de Investigaciones y Estudios Superiores en Antropología Social
}

En términos generales, sabemos que los códices mixtecos prehispánicos narran la historia de los principales señoríos que dominaban la porción oeste del actual estado de Oaxaca durante el periodo Posclásico. Pero esta aseveración es demasiado simple, ya que en los códices podemos encontrar desde mitos de origen hasta detalladas biografías de importantes gobernantes que realizaron actividades de índole política, guerrera o ritual. ${ }^{1}$ En efecto, por medio de un riguroso análisis de la iconografía plasmada en estos documentos pictóricos es posible distinguir un número importante de objetos, instrumentos o emblemas vinculados al poder y a la autoridad de los gobernantes. Algunos de estos objetos estaban imbuídos de una profunda significación religiosa, mientras que otros formaban parte de la acción política del soberano en su ejercicio cotidiano del poder.

A pesar del gran número de códices mixtecos que sobrevivieron a la Conquista, una de las problemáticas que existen para su estudio y para la identificación de los símbolos de poder es el escaso número de fuentes escritas realizadas en la zona por los españoles. Esto es, para la región mixteca no hay textos de la talla de Sahagún, Landa o Las Casas, por lo cual no existe una base firme que nos ayude a corroborar la lectura o interpretación de una buena cantidad de representaciones. De esta manera, para nuestro estudio recurrimos a los datos provenientes de la zona maya para crear marcos plausibles de interpretación para un grupo de objetos e instrumentos empleados por los gobernantes mixtecos antes de la conquista española. Por tanto, el objetivo central del presente artículo es identificar una serie de elementos que formaron parte de la acción ritual y política de los señores mixtecos y compararlos con un grupo de objetos análogos presentes entre diversos grupos mayas del periodo Clásico para que, de esta manera, puedan proporcionarnos una vía de interpretación factible ante la complejidad de los signos registrados en los documentos pictóricos.

\footnotetext{
${ }^{1}$ Los manuscritos prehispánicos que sobrevivieron a la conquista española son: el Códice Bodley, el Códice Nuttall, el Vindobonensis, Selden y Colombino-Becker. Aunque rigurosamente el Códice Selden fue terminado a mediados del siglo xvı, se considera de origen prehispánico debido a la nula influencia española que hubo en su elaboración.
} 


\section{Cetros y bastones de mando}

Son diversos los objetos que suelen aparecer en los códices mixtecos para señalar el poder y la autoridad de los gobernantes, pero al estudiar este tipo de elementos nos dimos cuenta de que no únicamente marcan el estatus de los personajes representados, sino también nos señalan una serie de actividades que llevaban a cabo los dignatarios a lo largo de su vida.

Las insignias y atributos empleados por los soberanos como distintivos de su rango y jerarquía suelen aparecer en contextos genealógicos, políticos, militares y tal vez jurídicos; así, la acción del gobernante no estaba circunscrita a una actividad específica, sino comprendía una amplia gama de quehaceres que iban desde el aspecto cotidiano hasta el ritual.

Tanto en Mesoamérica como en otras partes del mundo uno de los principales atributos del gobernante es representado por el cetro, pues a nivel universal el cetro simboliza el eje del mundo y el centro del cosmos; de tal modo, el soberano que lo porta se constituye a sí mismo como eje rector de ese universo. Según nos dice Mercedes de la Garza: "El cetro es, a nivel universal, un modelo reducido del bastón de mando, símbolo vertical que representa primero al hombre y después al hombre poderoso y el poder recibido de los dioses".

De acuerdo con la iconografía de diversas regiones de Mesoamérica, existía también una especie de modelo o figura que asemejaba un cetro, el llamado "cetro maniquí", profusamente representado en las estelas y dinteles del área maya. Es posible que entre los gobernantes mixtecos haya existido un tipo de elemento parecido a un cetro, pero estilísticamente distinto a los instrumentos mayas.

Entre los grupos mayas del periodo Clásico, el "cetro maniquí" constituía uno de los principales atributos de poder de los gobernantes. La forma de este cetro era de una figurilla de cuerpo entero con la cara de un dios narigudo, cuya pierna se transformaba en una larga cabeza de serpiente (figura 1). La pequeña figura representa al dios $\mathrm{K}$ [kawiil], numen conocido en el periodo Posclásico como Bolon Dz'acab, y que fundamentalmente se reconoce por su larga nariz bifurcada y ornamentada que parecía simbolizar a las hojas de maíz. ${ }^{3}$

Por sus características serpentinas, De la Garza considera al dios K como un ser estrictamente vinculado a la tierra, a la vegetación y a la sangre. Pero, además de relacionarse con la sangre del acto sacrificial, el dios K representa a la sangre del linaje de los gobernantes, razón por la cual se materializaba en cetro y se convirtió en una insignia de poder. ${ }^{4}$

Clemency Coggins, por su parte, menciona que el cetro maniquí identifica el linaje gobernante y la descendencia, pero también, en ciertos contextos cere-

\footnotetext{
2 De la Garza, "El puesto del gobernante en el cosmos y sus ritos de poder", p. 251.

${ }^{3}$ De la Garza, El universo sagrado de la serpiente entre los mayas, p. 207.

${ }^{4}$ Ibid., p. 208.
} 
moniales, es una alegoría del onanismo. ${ }^{5}$ Para llegar a esa conclusión, Coggins relaciona el glifo "mano que esparce" con una serie de significados vinculados con semen. Aunque este glifo suele aparecer en algunas estelas donde el gobernante sostiene el cetro maniquí, en las escenas donde no aparece tal glifo el cetro puede significar simplemente linaje noble. ${ }^{6}$

Estas complejas connotaciones del cetro

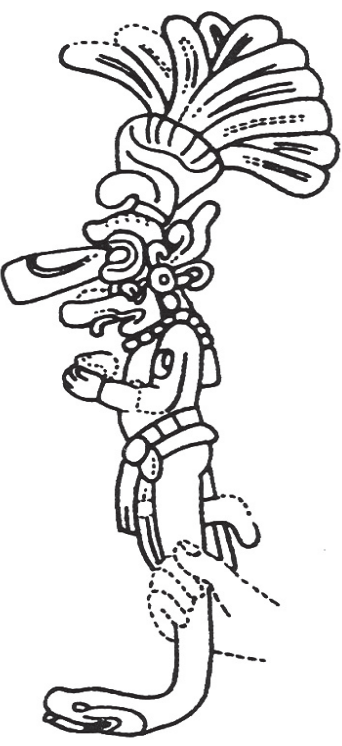

Figura 1. Dintel 53 de Yaxchilán. maya o Canhel, como también se le conoce, no parecen estar reflejadas en la imaginería de los grupos mesoamericanos del periodo Posclásico. En los documentos pictográficos del centro de México o del área oaxaqueña, los gobernantes no suelen llevar ningún tipo de atributo que pudiera relacionarse con un cetro. Los señores mexicas, por ejemplo, no aparecen casi en ninguna fuente portando alguna especie de cetro. Ni fray Bernardino de Sahagún en sus ilustraciones del Códice Florentino ni fray Diego Durán en su Historia de las Indias se refieren o llegan a representar al tlahtoani con un símbolo parecido.

Tampoco contamos con escenas en los códices que muestren al soberano portando tal instrumento; por ello podemos afirmar, en términos generales, la total inexistencia de este elemento dentro del repertorio de símbolos de poder empleados por los gobernantes mexicas.

Creo que la única excepción de lo recién mencionado se encuentra en el Códice Azcatitlan y en el Códice García Granados, documentos en los cuales se representa a los señores de Tenochtitlan y Tlatelolco sosteniendo precisamente unas largas lanzas a manera de báculo o cetro como insignia de poder (figura 2). En la página 13 del Azcatitlan se muestran las entronizaciones de Acamapichtli y Cuacuauhpitzahuac como tlahtoque de las nuevas ciudades gemelas del Valle de México. A los dos personajes les son entregados diversos objetos como parte de la ceremonia real: el copilli o diadema, una tilma o manta, un collar de oro y una larga lanza o báculo. De hecho, la lanza aparece invariablemente en todas las representaciones de los tlahtoque mexica en el Códice Azcatitlan, desde Acamapichtli hasta Moctezuma II, como parte de su símbolo de poder junto con el asiento real y la diadema (figura 3). Lo extraño de todo ello es que ni fray Bernardino de Sahagún ni Torquemada o Durán mencionan para nada la presencia de esta lanza como

${ }^{5}$ Coggins, "The Manikin Scepter: Emblem of Lineage”, p. 133.

6 Ibid., p. 141. 


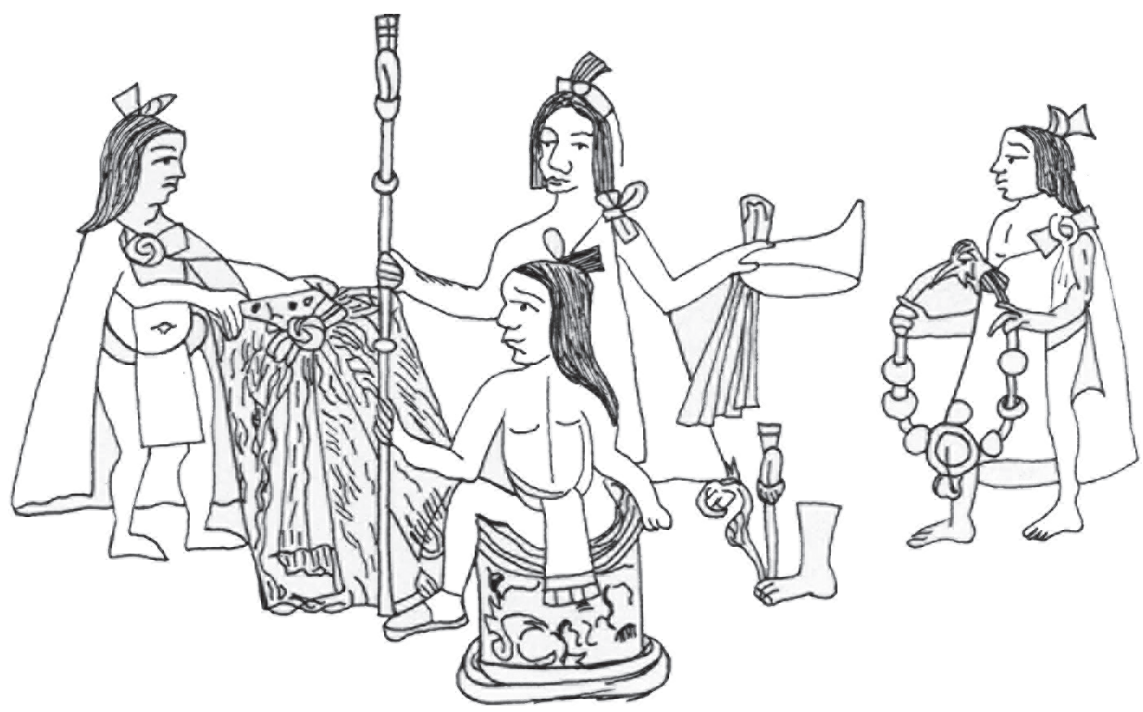

Figura 2. Códice Azcatitlan, 13.

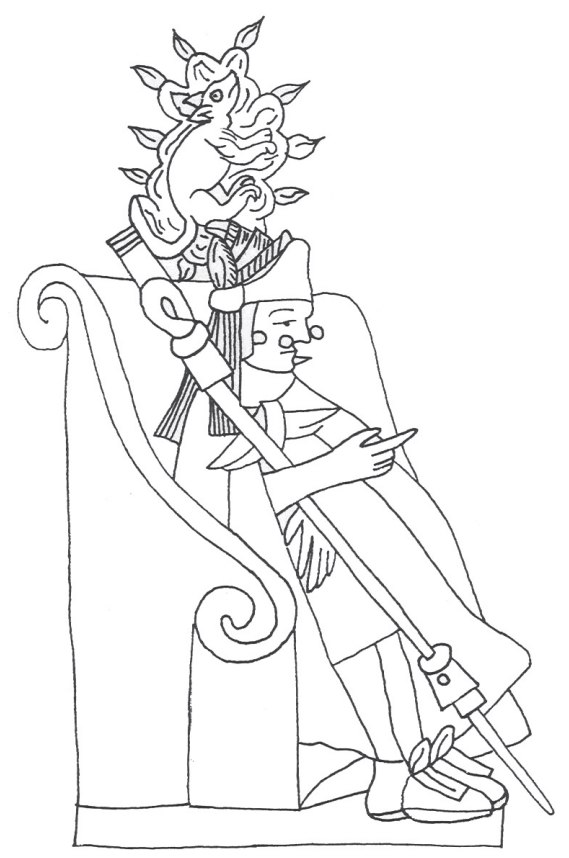

Figura 3. Códice Azcatitlan, 21. 
parte de las insignias o símbolos que les eran entregados a los gobernantes en el momento de su entronización. Tampoco Juan Bautista de Pomar, en su descripción sobre "la jura" o toma del poder del tlahtoani, habla de alguna lanza o báculo entre los objetos proporcionados al nuevo señor. ${ }^{7}$

Por lo tanto, si consideramos que el Códice Azcatitlan o el García Granados fueron elaborados ya en el periodo colonial, es factible pensar que los tlacuilos nahuas buscaron equiparar a los señores mexicas con los reyes europeos al pintarlos sobre grandes tronos con brazos y empuñando enormes cetros a manera de lanzas o flechas, estableciendo con ello una especie de símil entre los gobernantes mexicanos y los del viejo mundo.

Sin embargo, queda aún la posibilidad de que las lanzas sean una representación estilizada de los dardos o flechas que sí eran utilizados como símbolos de poder por otros grupos mesoamericanos y que de manera tardía llegaron a utilizarse entre los nahuas de Tenochtitlan-Tlatelolco.

Deseamos ahora centrar nuestra atención en un tipo de elemento que hemos identificado en los códices mixtecos y que suponemos es una representación de un emblema de poder.

En el Códice Nuttall aparece un objeto capaz de ser llevado por hombres y mujeres; consiste en una barra corta o pequeño palo que se ensancha en forma cuadrangular en la parte superior y está rematada por diversas tiras de colores que parecen surgir a manera de abanico (figura 4). Las tiras de colores parecen representar plumas debido a la gran afinidad que muestran con los tocados de los grandes señores. La sección central de este tipo de barra o palo se encuentra adornada con pequeños cuadrados de color amarillo al parecer sostenidos por una placa rectangular de color azul o rojo (figura 5).

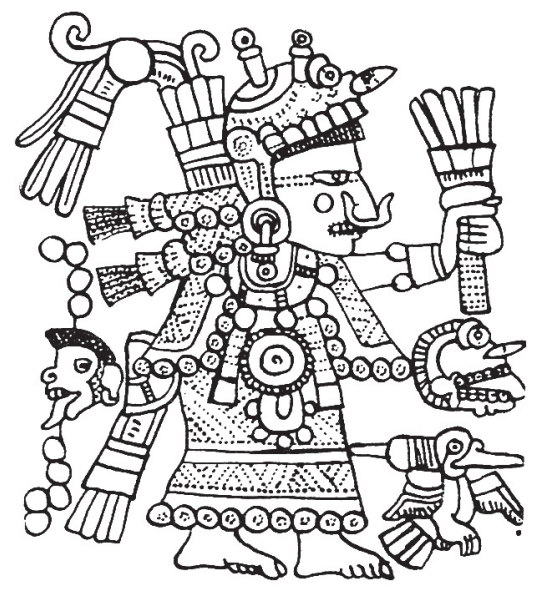

Figura 4. Códice NutTall, 6-III.

${ }^{7}$ René Acuña (editor), Relaciones Geográficas del siglo xVI: México, t. 3, p. 78. 
Proponemos que la figura llevada por estos personajes simboliza una especie de cetro o insignia únicamente empuñada por los gobernantes. Por ejemplo, las señoras 5-Hierba y 10-Águila, esposas del señor 8-Viento, "Águila de Pedernales", llevan un objeto parecido al ya descrito, pero su mango se convierte en una garra de águila (figura 6). De que se trata del mismo elemento no tenemos duda, pues la parte superior se encuentra adornada con las plumas o tiras de colores que salen de los cuadrados amarillos. Este tipo de cetro es llevado por varios personajes a lo largo del Códice Nuttall, como por ejemplo la señora 3-Pedernal "Quechquemitl de Concha" (figura 7); o el señor 5-Perro "Cola de Coyote", gobernante de la primera dinastía de Teozacoalco (figura 8).

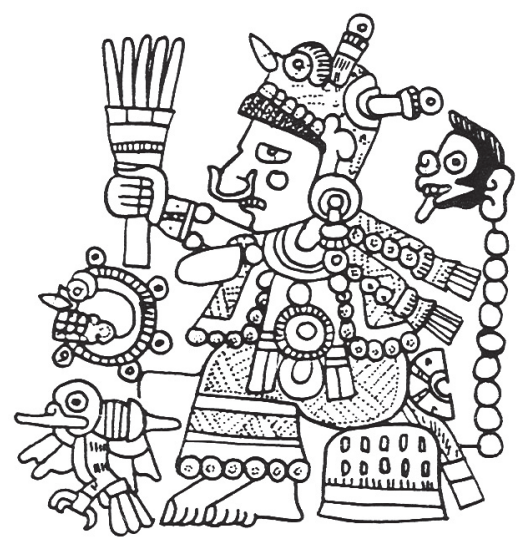

Figura 5. Códice Nuttall, 10-II.

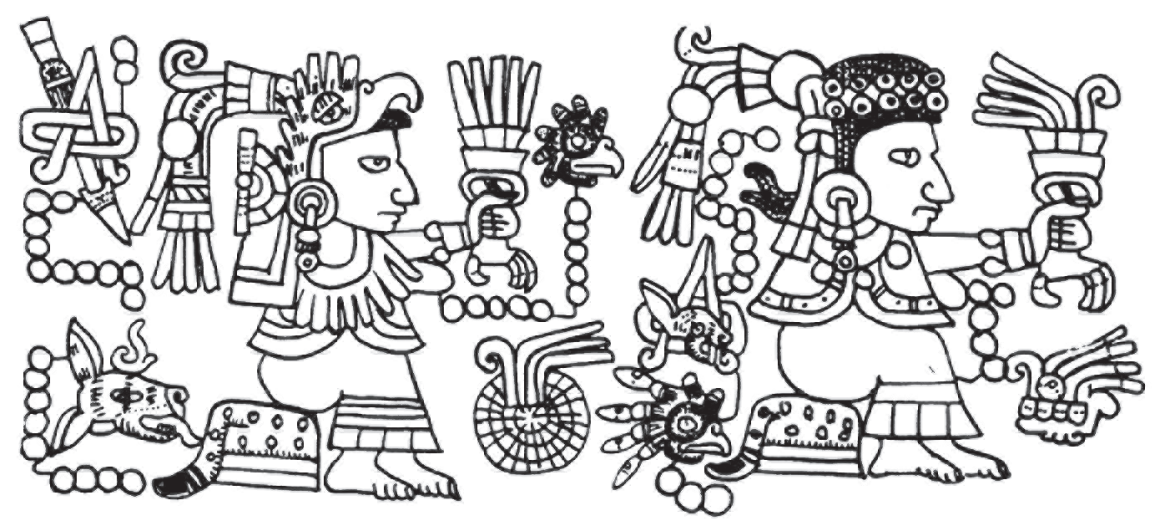

Figura 6. Códice Nuttall, 6-I. 

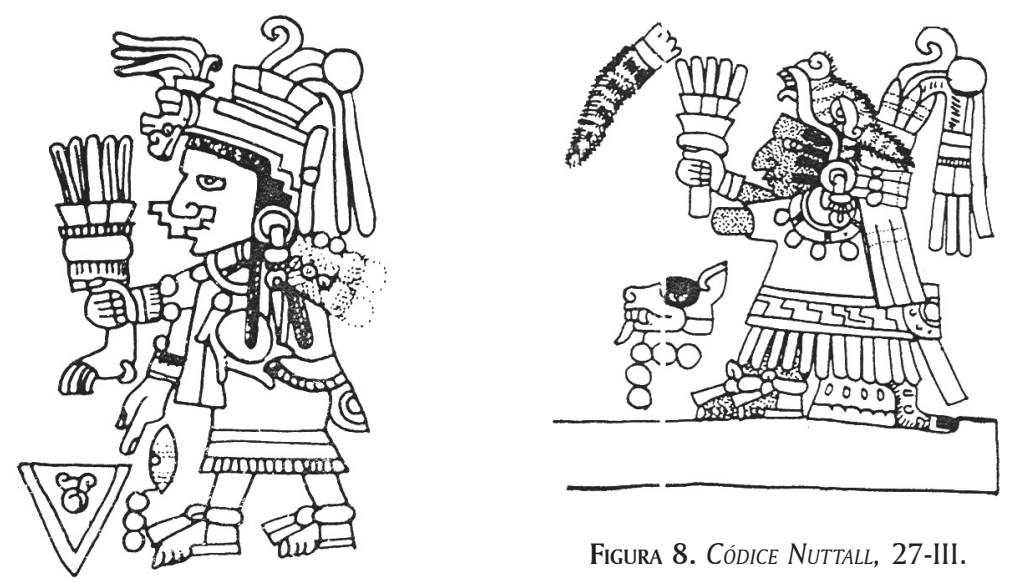

Figura 8. Códice Nuttall, 27-III.

Figura 7. Códice Nuttall, 15-I.

Claramente podemos advertir que la figura aludida no es un sobrenombre o antropónimo de los personajes, pues fácilmente pueden distinguirse los glifos directamente referidos al nombre del gobernante. Incluso, el objeto identificado como cetro a veces está adornado con flores o su mango puede estar forrado con piel de jaguar (figura 9).
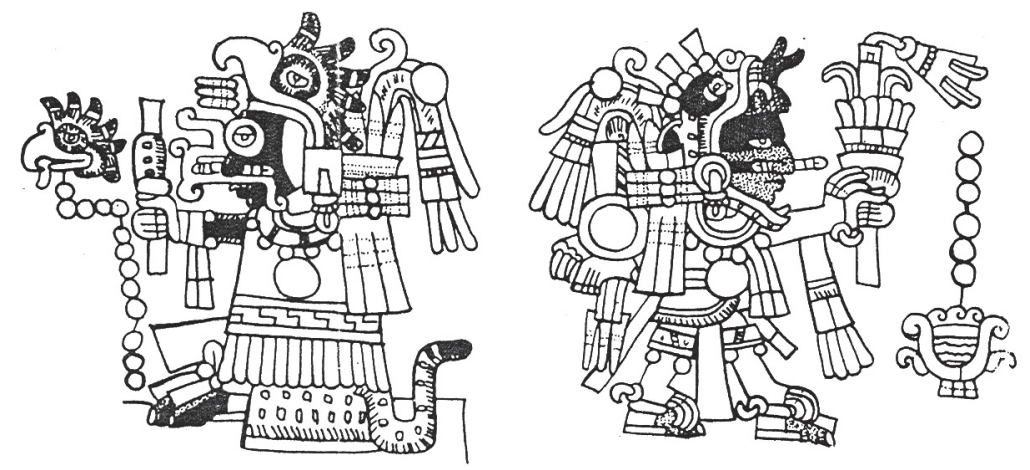

Figura 9. Códice Nuttall, 30-I y II.

Nos parece, entonces, que el objeto identificado bien podría representar una especie de cetro o insignia de poder únicamente llevada por los señores o gobernantes. El contexto en el que aparece este objeto es completamente adecuado para un emblema de poder. El señor o señora que lo porta aparecen sentados sobre cojines forrados de piel de jaguar o, en ocasiones, se dibuja en la mano del soberano cuando se encuentra sentado dentro del palacio, otorgándole con ello un alto estatus o dignidad al personaje que lo ostenta (figura 10). 


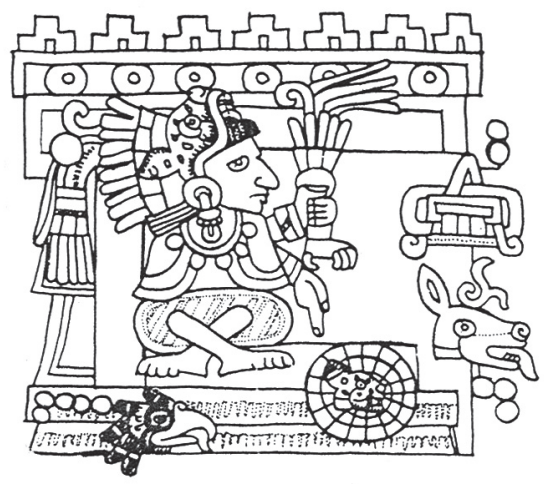

Figura 10. Códice Nuttall, 27-I.

\section{Bastones cosmológicos y rituales}

En la iconografía de los códices podemos identificar diversos tipos de bastones relacionados con los cultos o ceremonias particulares que vinculaban al gobernante con el mundo sagrado de los dioses. El estudio de estos bastones ha llamado la atención de algunos de los investigadores dedicados a los códices mixtecos, pero ninguno ha profundizado lo suficiente en su simbolismo o en los contextos específicos en donde suelen aparecer. Alfonso Caso se había dado cuenta de la presencia de estos elementos a los que denominó "Bastones de Venus", debido quizá a la forma de quincunce o cinco puntos en su parte superior y que evoca a las representaciones mesoamericanas relacionadas con este planeta. Sin embargo, Caso no se adentra en su significado y únicamente se limita a registrar su aparición a lo largo de los códices. ${ }^{8}$

Maarten Jansen intenta ir un poco más allá e interpreta los bastones como símbolos de autoridad o de poder dinástico, llamándolos concretamente "Bastones de mando", pues aparecen principalmente como señal de la dignidad y/o autoridad de los gobernantes. ${ }^{9}$

No obstante, como más adelante demostraremos, si bien estas varas o bastones están vinculados con el origen y entronización de los gobernantes, no funcionan precisamente como símbolo de autoridad o de poder político, sino como elementos necesarios para el orden cósmico y el establecimiento de la dinastía o linaje.

\footnotetext{
${ }^{8}$ Alfonso Caso, Reyes y reinos de la mixteca, t. 1, p. 33.

${ }^{9}$ Ferdinand Anders, Maarten Jansen y Gabina Aurora Pérez: Crónica Mixteca: el rey 8-Venado Garra de Jaguar y la dinastía de Teozacoalco-Zaachila. Libro explicativo del llamado Códice Zouche-Nuttall, p. 8586 , nota 2 .
} 
El denominado "Bastón de Venus" se compone de diversos elementos o atavíos que debemos analizar primero antes de proponer una significación adecuada (figura 11). El bastón o vara se puede dividir en tres partes. La sección central, que quizá es la más importante, está conformada por una especie de rosetón de color rojo; su interior está adornado con cinco círculos grandes que contienen a su vez un pequeño círculo al centro cada uno. De la parte inferior de este rosetón cuelgan tiras o bandas de color rojo cuyo número varía de dos a tres, según la representación. Cada banda o tira se encuentra unida a un pequeño círculo azul sobrepuesto a un rectángulo amarillo y largas tiras de color rojo; en ocasiones, en la parte de abajo del rosetón una larga banda termina en flecos en lugar de las tres tiras o, incluso, el bastón se llega a representar sin ningún tipo de bandas en la parte inferior (figura 12).

Por último, en la parte superior del rosetón se levanta un largo penacho de plumas rojas acompañado de un gran pedernal colocado en forma enhiesta. Las plumas rojas que suelen caer por un lado del bastón están adornadas con pequeños círculos azules y rectángulos amarillos que parecen unidos a otras bandas alargadas semiredondas pintadas de blanco y negro.

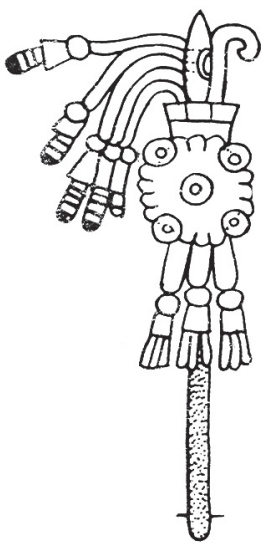

Figura 11. Códice NutTall, 18-II.
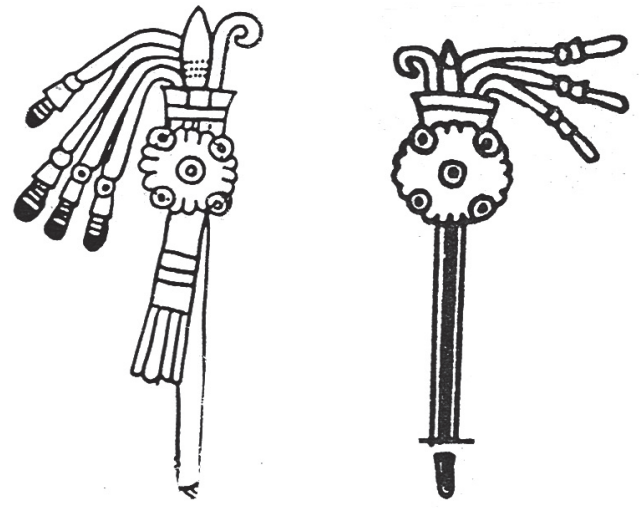

Figura 12. Códice Nuttall, 19 y Códice Vindobonensis, 44-III.

En otros códices, como en el Colombino y Bodley, el rosetón de la parte central lleva los cinco círculos de color amarillo, pero sin los pequeños círculos centrales, e incluso en el Códice Bodley se llega a representar este bastón sin los cinco círculos dentro del rosetón (figura 13).

De todos estos elementos descritos que dan forma al bastón, pienso, sin duda, que el elemento principal es el de la parte central. El gran rosetón rojo 
tiene colocados cinco puntos que evidentemente evocan una representación de los cuatro rumbos del universo y su centro. La disposición misma de los cinco puntos en el rosetón confirma esta idea: cuatro puntos están colocados en los extremos del rosetón, conformando una especie de cruz, y justamente al centro se localiza un quinto punto. Entonces, es muy probable que la parte principal del bastón se refiera al ordenamiento cósmico según la visión de muchos pueblos mesoamericanos, incluyendo desde luego a los mixtecos: los cuatro cuadrantes o rumbos del universo con el centro como quinto rumbo.
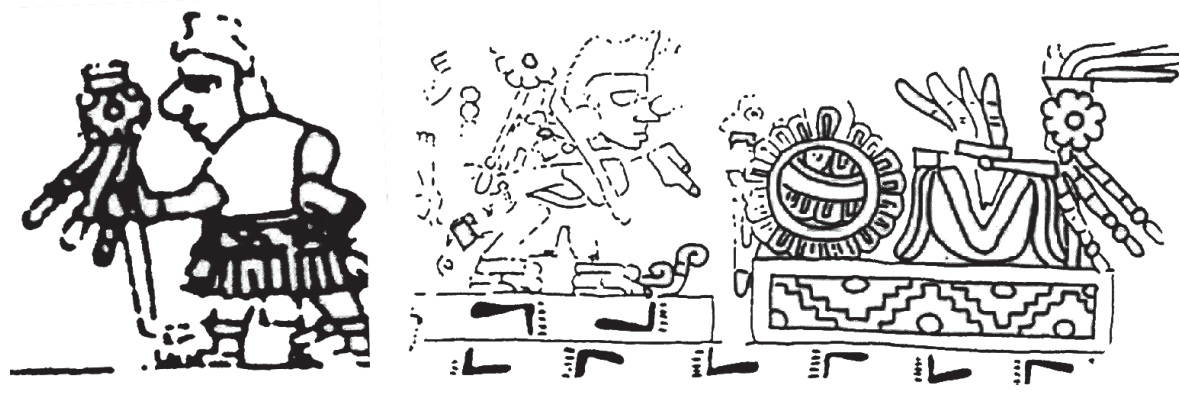

Figura 13. Códice Colombino, 6-III y Códice Bodley, 9-I.

En el mundo maya existen algunas figuras de pequeños bastones que también pueden representar el axis mundi y los cuatro sectores cósmicos. Tal es el caso, por ejemplo, del dintel 5 de Yaxchilán, donde se encuentra un gobernante portando dos objetos en forma de cruz en cuya parte superior está colocada un ave ${ }^{10}$ (figura 14). De acuerdo con De la Garza, la forma cuatripartita de este cetro funciona como una representación de los cuatro puntos del universo, por lo cual existe una analogía interesante con el bastón mixteco (que podría simbolizar un modelo reducido de la cosmovisión mesoamericana). Por esta razón, hemos denominado como "bastón cosmológico" a este elemento singular que aparece en las ceremonias y rituales plasmados en los códices mixtecos.

Por lo pronto, hay todavía otros elementos susceptibles de ser analizados en el bastón mixteco. Nos referimos al adorno de plumas rojas colocado encima del rosetón (figura 11). Muy probablemente, las plumas rojas pertenecen a una guacamaya y contrastan notablemente con las plumas verdes del "Bastón del Bulto de Xipe", las cuales pertenecen verosímilmente a un quetzal. En un momento

${ }^{10}$ De la Garza, op. cit., p. 251. 


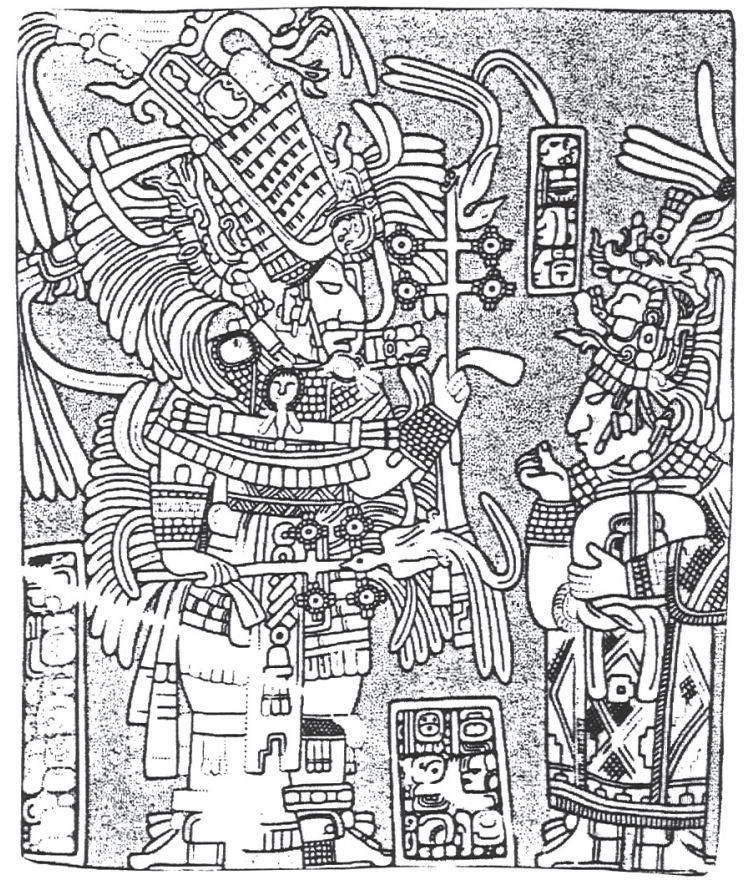

Figura 14. Dintel 5 de YaxChilán.

más hablaremos sobre este último bastón, que aparece siempre junto al ahora denominado "cosmológico", pero ahora queremos destacar el significado de las plumas rojas como un posible atributo solar. Efectivamente, si bien es cierto que entre los mixtecos no hay indicios de una adoración particular a la guacamaya considerada como encarnación del fuego del Sol, tal y como existía entre los mayas, ${ }^{11}$ al menos el color de las plumas y el rosetón nos recuerdan las representaciones del dios solar mixteco llamado 1-Muerte, quien siempre aparece en los códices con su cuerpo pintado de color rojo (figura 15).

Aunque el dios 1-Muerte no lleva atavíos con plumas de guacamaya, la asociación del color rojo con las plumas del bastón pudiera contener una significación solar; pero también es posible que el rojo simbolice la sangre y haya una relación directa con el cuchillo de pedernal representado en la parte superior del bastón. Sin embargo, no hay una relación directa del bastón cosmológico con los sacrificios, pues los contextos en donde aparece este bastón no están vinculados directamente con dichas ceremonias, salvo una sola excepción.

${ }^{11}$ De la Garza, Aves sagradas de los mayas, p. 50. 


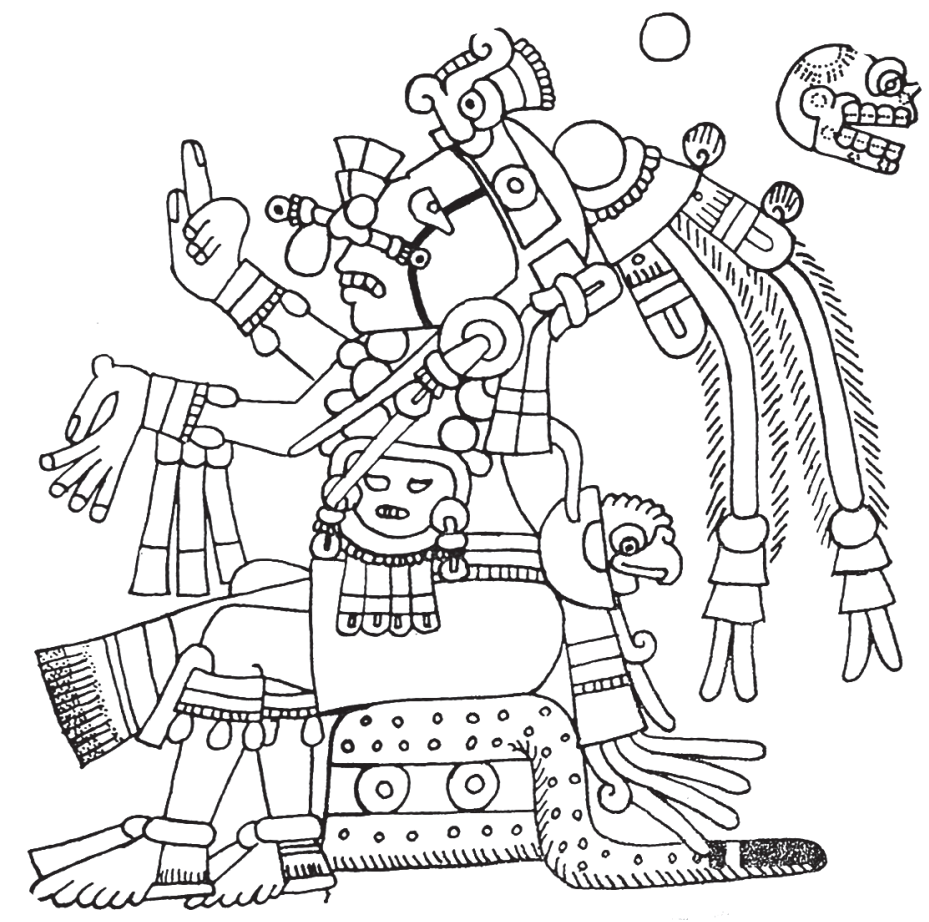

Figura 15. Códice NutTall, 79-I.

Pero antes de establecer el significado del Bastón Cosmológico es necesario analizar el otro bordón con el que aparece estrechamente relacionado: el Bastón del Bulto de Xipe (figura 16). Este elemento también está conformado por una vara o palo con un bulto sagrado sobrepuesto, conocido también como Bulto de Xipe. Este envoltorio tiene una forma alargada y rectangular, atravesado en su sección central por tres tiras terminadas en puntas o conos que salen de un anillo o rueda. Los colores rojo y blanco que aparecen en el envoltorio están estrechamente relacionados con el culto a Xipe; por ello, este otro bastón podría relacionarse directamente con dicha deidad.

El Bastón del Bulto de Xipe, al igual que el Bastón Cosmológico, suele aparecer adornado en la parte inferior con tiras o bandas alargadas de color blanco y rojo pero, sin duda, lo más interesante es que lleva un penacho en la parte superior compuesto de plumas de ave de un color diferente al del Bastón Cosmológico (figura 16). En efecto, el Bastón de Xipe está adornado con plumas verdes, muy probablemente de quetzal, que salen por la parte superior del envoltorio rectangular. Como sabemos, el quetzal es una de las aves con mayor simbolismo 


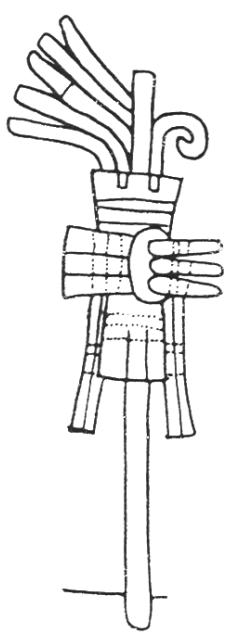

Figura 16. Códice Nuttall, 18-II. entre muchos pueblos mesoamericanos. Por sus características particulares, tales como su larga cola de plumas verdes o su hábitat en las cimas de las montañas, el quetzal fue elegido como representante de la deidad celeste entre diversos grupos mayas de la época prehispánica. ${ }^{12}$ Existen numerosas representaciones del quetzal que lo vinculan con el ámbito celeste, el espacio generador y el lugar de origen de la vida y del hombre. ${ }^{13}$ De esta manera, las plumas de quetzal están estrechamente relacionadas con lo divino, lo sagrado y lo precioso en el mundo mesoamericano. Por lo tanto, los dos más importantes bastones representados en las historias y genealogías de los soberanos mixtecos parecen tener un significado particular de acuerdo con los elementos iconográficos que los componen. Efectivamente, retomando la idea de que el bordón o vara

es un objeto vertical que simboliza el eje del mundo alrededor del cual gira el cosmos, los bastones representarían el esquema cosmológico en la tierra, es decir, el modelo de la cosmovisión mesoamericana en manos de los hombres. Si bien, por ejemplo, los árboles funcionan también como eje o centro del mundo, queremos proponer que el Bastón Cosmológico mixteco, al igual que el Bastón del Bulto de Xipe, son el axis mundi encarnado sobre la tierra.

Es importante señalar, siguiendo a De la Garza, que el árbol es entre los mayas, así como en otras religiones, el lazo de unión del cosmos y que abarca los tres planos del universo: "las raíces son el inframundo, el tronco y las ramas el nivel terrestre, y el ave posada en lo alto, el cielo". ${ }^{14}$ Esta misma autora nos habla de múltiples representaciones del axis mundi como, por ejemplo, el árbolcruz-serpiente de la lápida del Templo de las Inscripciones o el motivo central del tablero del Templo de la Cruz, ambos de Palenque, en los cuales existe un esquema definido por un árbol cósmico en forma de cruz sobre el cual se posa un pájaro-serpiente con cabeza del dios K. ${ }^{15}$

Esta concepción del universo no es exclusiva de los mayas, sino también fue compartida por otros grupos mesoamericanos. En los códices provenientes del sur de Puebla y norte de Oaxaca, como los Fejérváry-Mayer y Borgia, también en-

\footnotetext{
12 Ibid., p. 14.

13 Ibid., p. 41.

${ }^{14}$ Ibid., p. 24.

15 Ibid., pp. 26-28.
} 
contramos este modelo del universo conformado por árboles. La página 1 del Fejérváry-Mayer precisamente muestra los cuatro rumbos del universo colocados en forma de cruz; dentro de cada uno de los rumbos o puntos cardinales está colocado un árbol cósmico con un ave particular posada en su copa (figura 17).

Las páginas 49-52 del Códice Borgia también representan las cuatro regiones del mundo simbolizadas por los cuatro árboles con sus respectivas aves, y en los códices mixtecos, como el Colombino, también existen escenas donde se vinculan árboles y puntos cardinales. Por lo tanto, si los árboles direccionales funcionan como ejes del mundo dentro del enorme marco conceptual del cosmos mesoamericano, entonces proponemos que muy posiblemente los bastones o varas fueron un reflejo tangible y portátil de ese cosmos indígena.

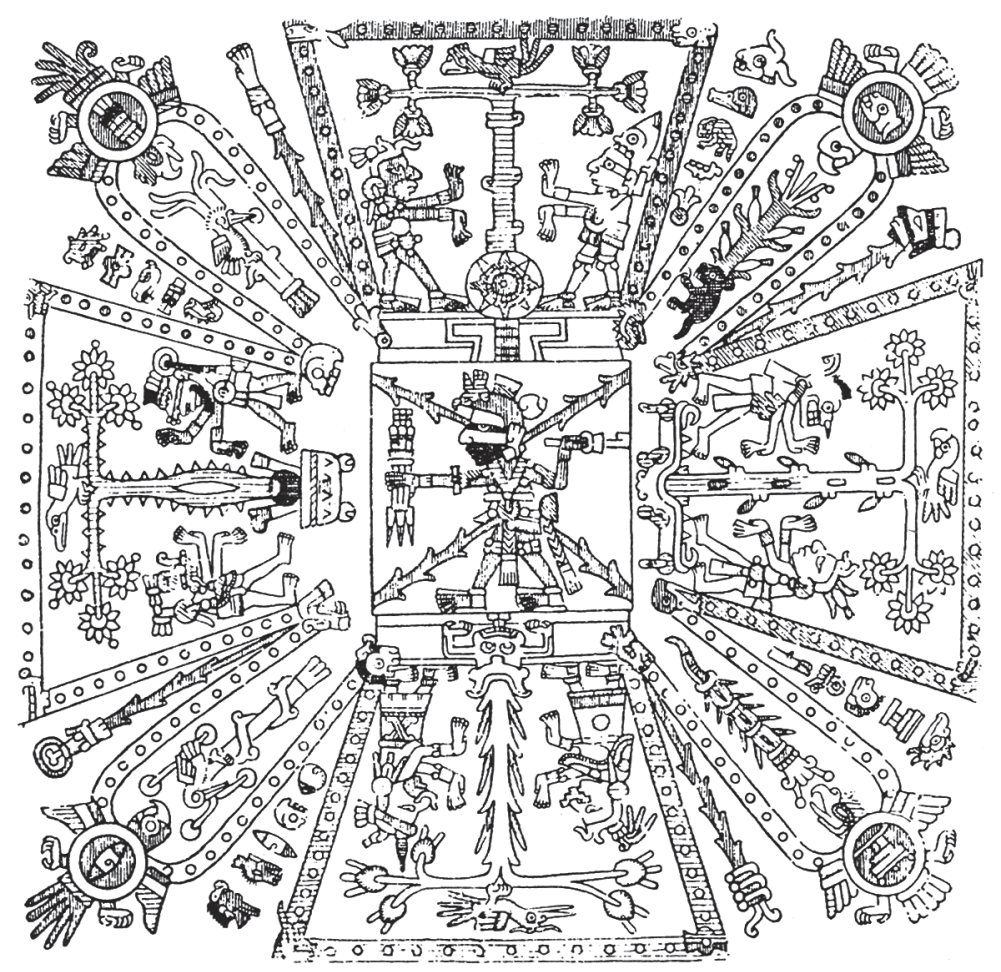

Figura 17. Códice Fejéváry-Mayer, 1. 
El bordón mixteco que aparece en los códices prehispánicos, y que hemos denominado Bastón Cosmológico, es precisamente un modelo terrestre y tangible de la cosmovisión mixteca. Este bastón es, en sí, la representación de un árbol o eje del mundo, donde su gran penacho simboliza al ave cósmica posada en lo más alto de las ramas de ese árbol y cuyas raíces se encuentran en la tierra en cuanto el bastón es hincado en la misma (figura 18).

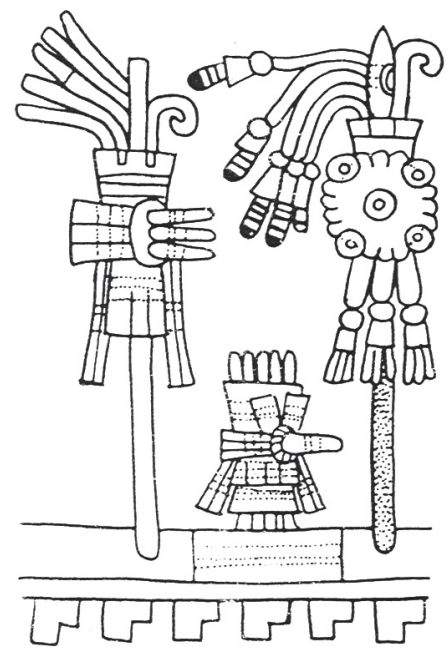

Figura 18. Códice Nuttall, 18-II.

El Bastón Cosmológico mixteco es, con su rosetón con cinco puntos y su remate de plumas rojas, un árbol o eje del mundo quizá asociado, incluso, con un rumbo del universo. Resulta particularmente interesante que en la misma página 1 del Códice Fejérváry-Mayer el portador del año correspondiente a la región del norte esté relacionado con una guacamaya. En efecto, del lado izquierdo de la cruz se localiza el rumbo del norte, donde el portador del año pedernal está colocado dentro de un círculo cargado por una guacamaya (figura 17). Y en la página 52 del Códice Borgia se encuentra la misma asociación de una guacamaya posada sobre un árbol y el glifo del año pedernal a un lado.

Esto es, quizá, lo que vemos en el Bastón Cosmológico: un penacho de plumas rojas, tal vez de guacamaya, sobre un largo pedernal que simboliza el bastón de la región del norte. Sin embargo, reconocemos que tenemos muy pocos elementos para poder comprobar esta propuesta, porque de ser así tendríamos entonces representados en los códices mixtecos cuatro bastones y no únicamente dos como lo hemos visto. Por lo tanto, no tenemos suficientes elementos 
para relacionar los bastones con los rumbos del universo; no obstante, creemos estar en lo correcto al relacionar el bastón con el eje del mundo o con un árbol cósmico, pues representaciones muy semejantes de báculos o cetros aparecen en el dintel 2 de Yaxchilán, donde los personajes llevan instrumentos en forma de cruz con flores y pájaros descendentes en lo alto que funcionan como símbolos o esquematizaciones de los árboles del axis mundi (figura 19).

Pero antes de dejar en claro las funciones específicas de los bastones mixtecos como elementos rituales o ceremoniales, es necesario analizar los contextos donde aparecen y así tener una mejor idea de su significación.

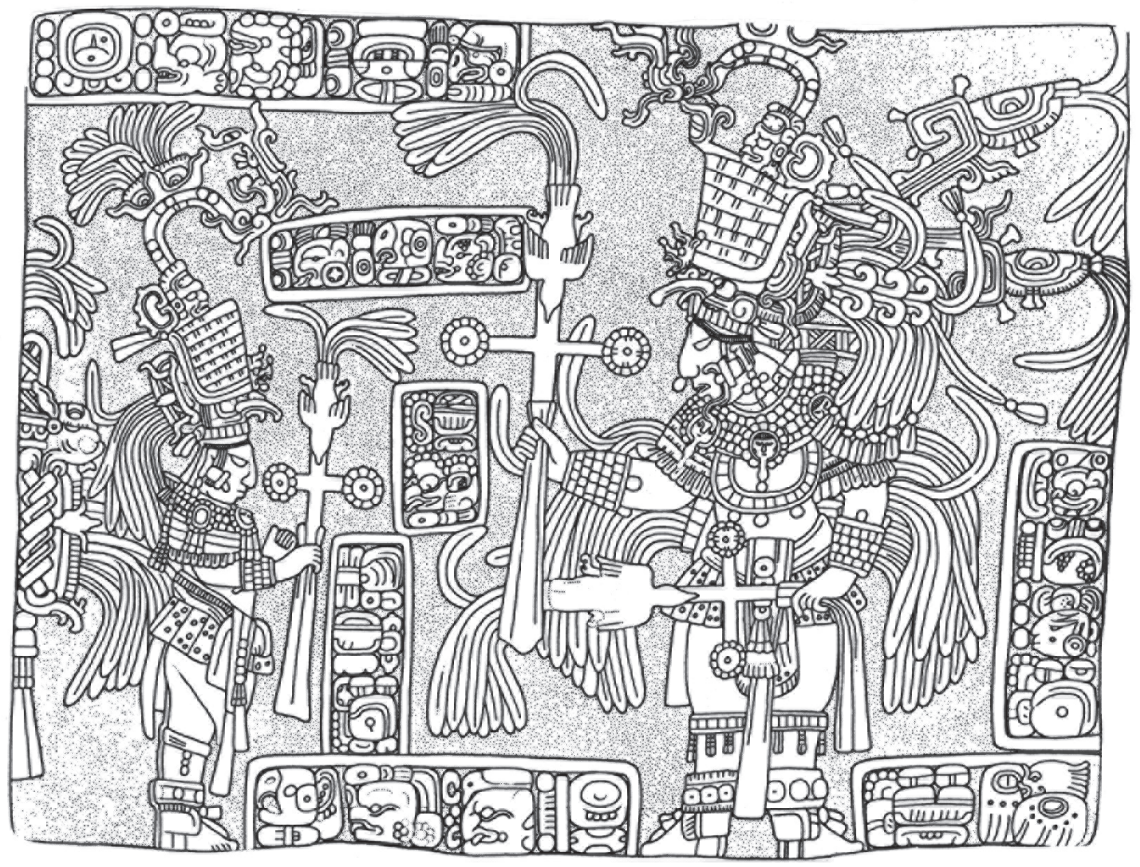

Figura 19. Dintel 2 de Yaxchilán.

\section{Contextos rituales}

El origen del Bastón Cosmológico se encuentra relatado en los códices mixtecos mismos. Su primera aparición coincide con el advenimiento de una de las deidades más importantes de la Mixteca, 9-Viento "Quetzalcóatl". En efecto, 
cuando Quetzalcóatl desciende del cielo por medio de una cuerda, lleva consigo una serie de objetos entregados a él por los dioses creadores (figura 20). Uno de estos objetos fue precisamente el Bastón Cosmológico, que incluso lleva cargando en el brazo izquierdo junto con otros elementos. Por lo tanto, el Bastón Cosmológico era un objeto divino, sagrado, creado por los dioses primigenios y depositado en la tierra por medio de Quetzacóatl para recibir el culto de los hombres.

Este carácter divino, sagrado, del Bastón Cosmológico va a quedar patente en la serie de contextos y ceremonias donde va a estar involucrado a lo largo de la historia de los señores mixtecos.

Un buen ejemplo de ello lo tenemos en las primeras escenas del Códice $\mathrm{Nu}$ ttall con el nacimiento del señor 8-Viento "Águila de Pedernales", cuyo origen se relata en las páginas 1 y 2 (figura 21). La narración completa nos muestra cómo el señor 8-Viento, para ser reconocido como soberano legítimo y fundador del linaje de Suchixtlán, debió hacerse acompañar de los símbolos sagrados creados por los dioses. Es decir, los diversos grupos de personajes que reciben y ofrendan a 8-Viento lo reconocen como su gobernante no solamente por su nacimiento prodigioso, sino también por los objetos divinos que lo acompañan: el bulto sagrado, el Bastón Cosmológico y el Bastón del Bulto de Xipe, transportados por un personaje de nombre 12-Lagarto y que acompaña a 8-Viento desde el momento de su nacimiento (figura 22).

Otro contexto ritual que nos habla mucho acerca de la significación y uso de los bastones lo hallamos en la página 16 del Códice Nuttall donde aparecen representados juntos el Bastón Cosmológico, el Bastón de Xipe y el bulto sagrado con los instrumentos para encender el fuego (figura 23). Otra escena similar se halla en la página 17, donde el Bastón Cosmológico y el Bastón de Xipe están colocados al pie del Templo de la Serpiente Emplumada, que contiene el envoltorio sagrado con los instrumentos para hacer fuego (figura 24). Esta última escena es muy importante pues acompaña al matrimonio de la señora 3-Pedernal con el señor 5-Flor, lo cual nos indica la fundación de un linaje y el origen de un culto en particular. Efectivamente, estas páginas del Nuttall que ahora nos ocupan tratan en general sobre la introducción o establecimiento del culto a Quetzalcóatl en la Mixteca Alta. Los personajes dedicados a este culto son la señora 3-Pedernal (madre), la señora 3-Pedernal (hija), el señor 5-Flor y los sacerdotes 10-Caña y 10-Zopilote, quienes son precisamente los encargados de llevar los objetos de culto en los que se manifiesta dicha deidad: el bulto sagrado de 9-Viento "Quetzalcóatl”, el Bastón Cosmológico, el Bastón de Xipe y el Bulto de Xipe. La señora 3-Pedernal (madre) incluso lleva en su atuendo atavíos relacionados con Quetzalcóatl, tales como el tocado de serpiente emplumada que lleva en la página 14 del Nuttall; de hecho, ella misma se transforma en serpiente emplumada para visitar a la "abuela" o diosa de los ríos, llamada en la Mixteca "1-Águila" (figura 25).

Precisamente sus acompañantes, los sacerdotes 10-Caña y 10-Zopilote, realizaron un gran ritual dedicado a los objetos sagrados en la página 17 (figura 26). 


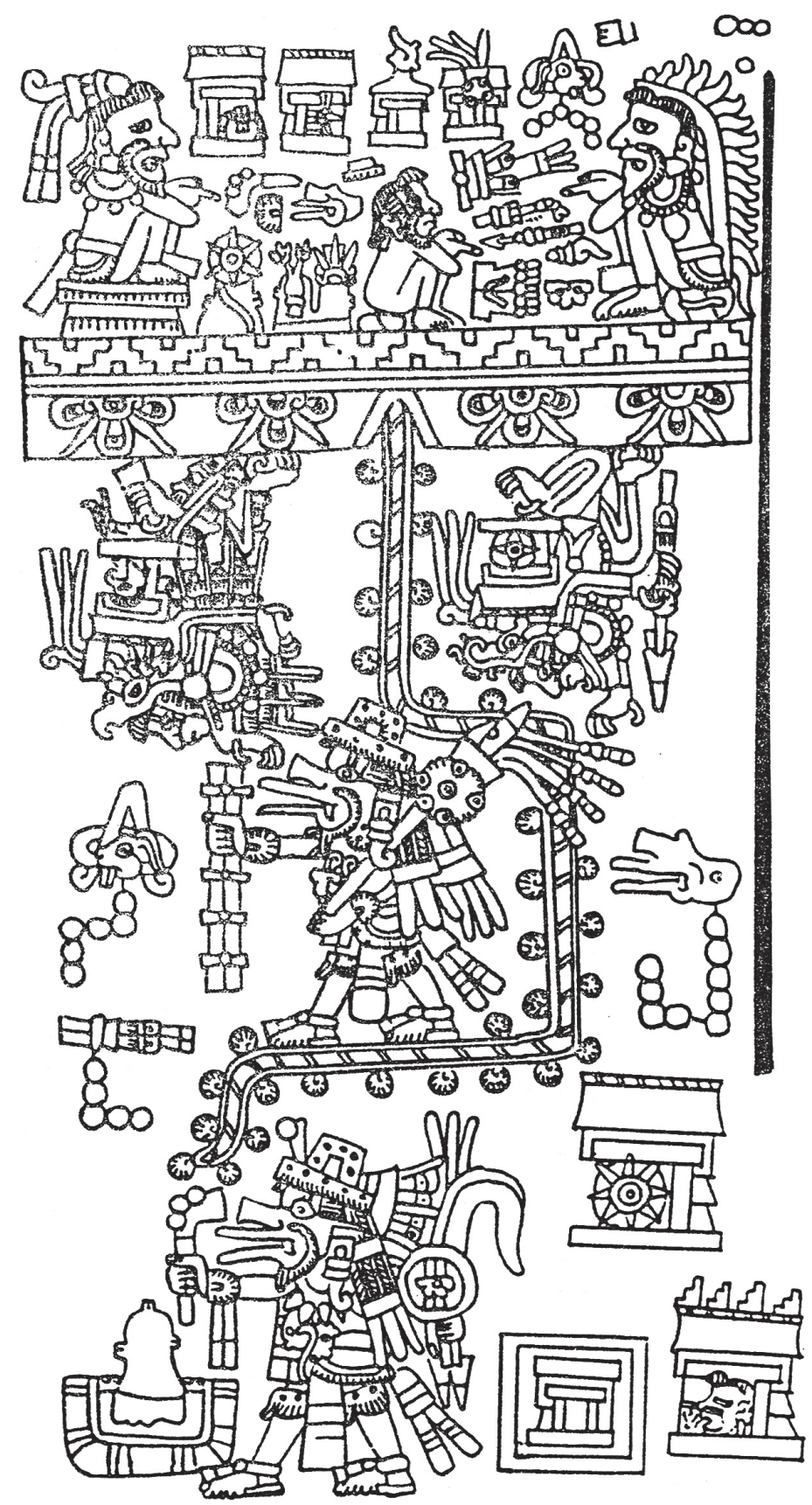

Figura 20. Códice Vindobonensis, 48. 


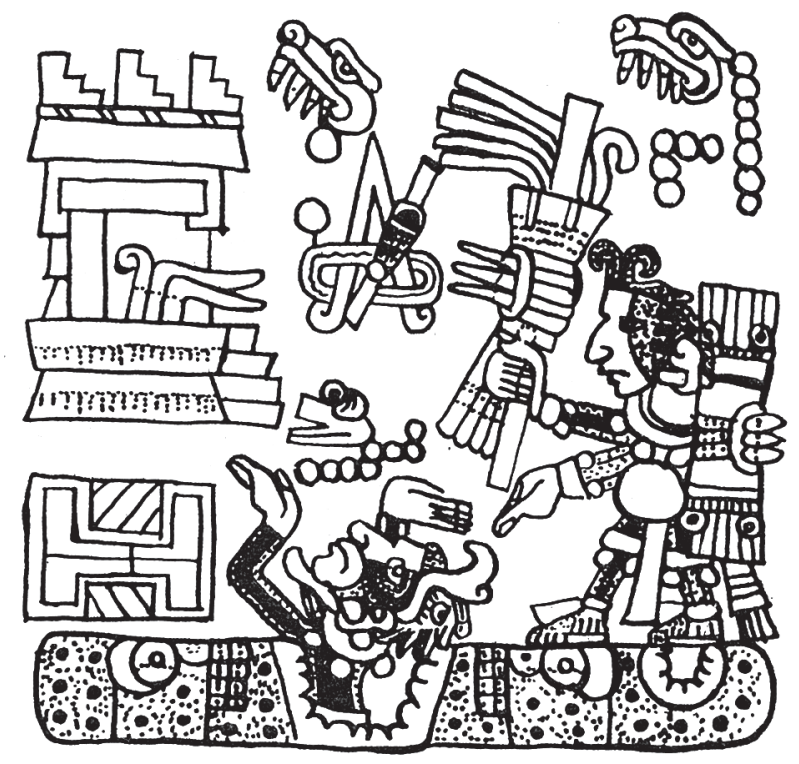

Figura 21. Códice NutTall, 1.

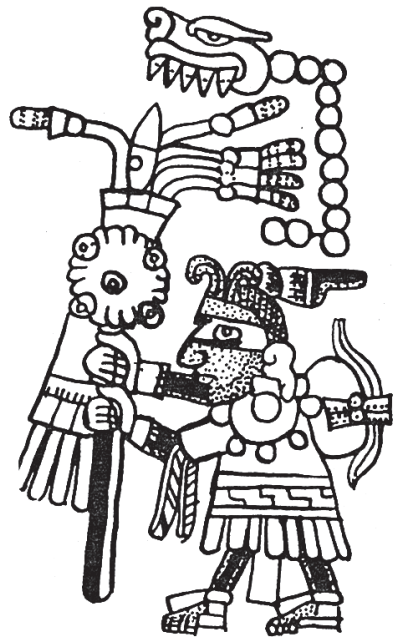

Figura 22. Códice NutTall, 2.

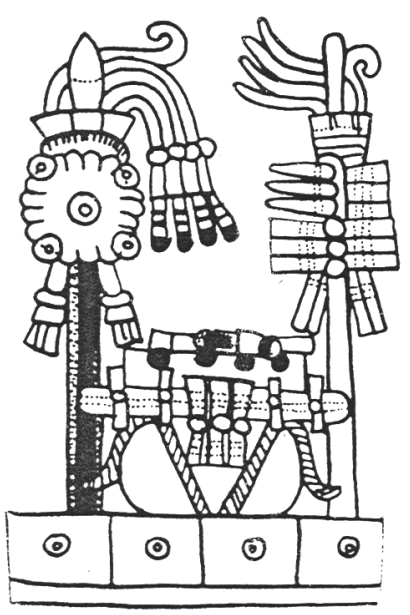

Figura 23. Códice NutTall, 16-III. 


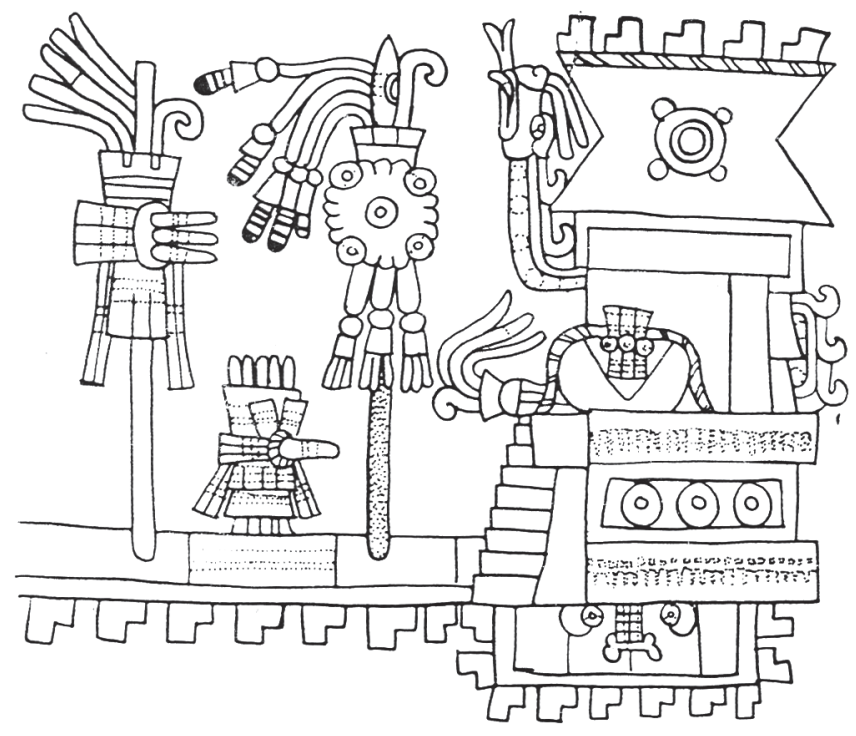

Figura 24. Códice Nuttall, 18-II.

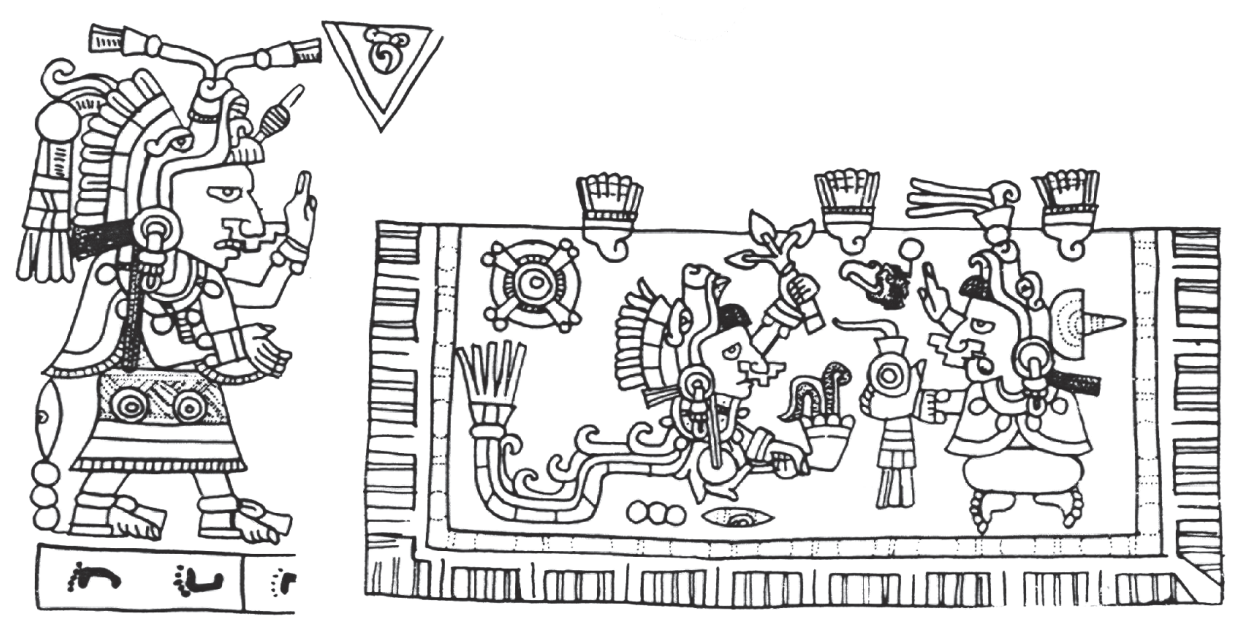

Figura 25. Códice Nuttall, 14 y 15-II. 


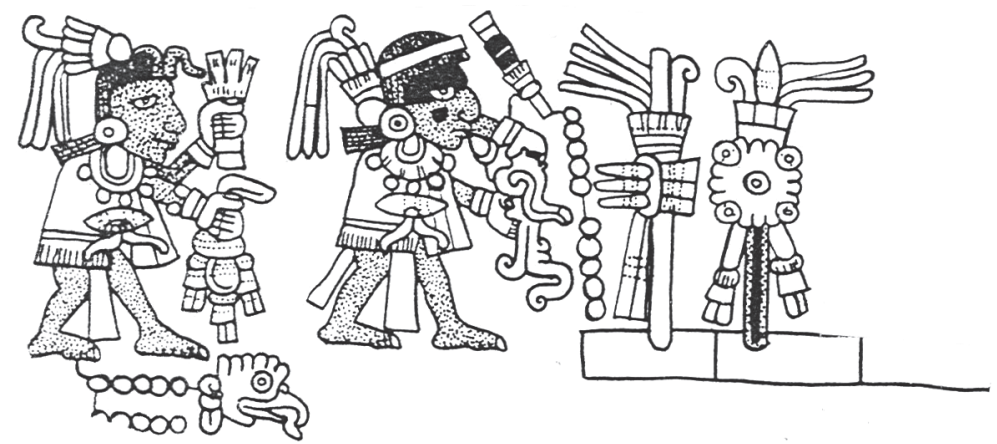

Figura 26. Códice Nuttall, 17-II.

Aquí advertimos cómo ambos sacerdotes se dirigen a los bastones sagrados y cómo el señor 10-Caña toca un caracol delante de ellos para su consagración. La gran ceremonia dedicada a los instrumentos divinos está presidida además por otro grupo de sacerdotes que encienden una gran hoguera en un pequeño adoratorio o basamento colocado dentro de un valle o planicie flanqueada por dos cerros.

Nos resta por analizar un último contexto en el que suelen aparecer los bastones ceremoniales y para ello debemos remitirnos a la vida del famoso gobernante 8-Venado "Garra de Jaguar". De acuerdo con diversos códices, este personaje fue hijo del sumo sacerdote de Tilantongo y como no pertenecía al linaje real, las posibilidades de 8-Venado para convertirse en gobernante eran remotas. Por ello, debió realizar una serie de actividades políticas y rituales para llegar a ser reconocido como soberano. Es el Códice Colombino, por ejemplo, el que nos relata con detalle el rápido ascenso de 8-Venado para obtener el señorío de Tututepec, el pueblo más importante de la Mixteca de la Costa. Al parecer, la intervención divina jugó un papel relevante para que 8-Venado alcanzara el señorío de Tututepec. Según el Colombino, dos importantes deidades le otorgaron la facultad de gobernar y fundar un nuevo linaje en el pueblo sureño de la costa; se trata de la señora 9-Hierba, diosa de la muerte, y del señor 1-Muerte, dios del Sol.

Después de reunirse con ambas deidades, 8-Venado emprende un largo viaje hacia la región de la costa llevando consigo los símbolos e instrumentos sagrados para establecerse en Tututepec. Entre los diversos objetos transportados se encuentra precisamente el Bastón Cosmológico, representado con los pequeños cinco círculos de color amarillo. Al parecer, el personaje que porta el Bastón Cosmológico se denomina 5-Lluvia, quien lleva además una bolsa con un gran caracol al frente. Este personaje llamado 5-Lluvia, "Montaña que Humea”, jugó un papel relevante para la entronización de 8-Venado en Tututepec, pues aparece como acompañante o asistente de este último. 
Probablemente 5-Lluvia tenía algún cargo sacerdotal, razón por la cual se le representa llevando el Bastón Cosmológico y acompañando a 8-Venado durante su peregrinación a Tututepec. En las páginas 3-III y 4-III del Colombino aparecen nuevamente juntos 8-Venado y 5-Lluvia realizando una serie de rituales y ofrendas en los lugares que simbolizan las cuatro regiones del universo (figura 27). Cada uno de estos sitios está simbolizado por un árbol que lo relaciona con un punto cardinal específico. Por lo tanto, 8-Venado y 5-Lluvia hacen ofrendas y ceremonias a los cuatro puntos cardinales llevando consigo el Bastón Cosmológico. Como hemos propuesto en párrafos anteriores, el Bastón Cosmológico representa precisamente los cuatro rumbos del universo y el centro; por lo que parece lógico que este mismo bastón sea llevado hacia los puntos cardinales en un acto simbólico para tomar posesión del señorío junto con sus linderos, situados hacia los cuatro rumbos del mundo. ${ }^{16}$

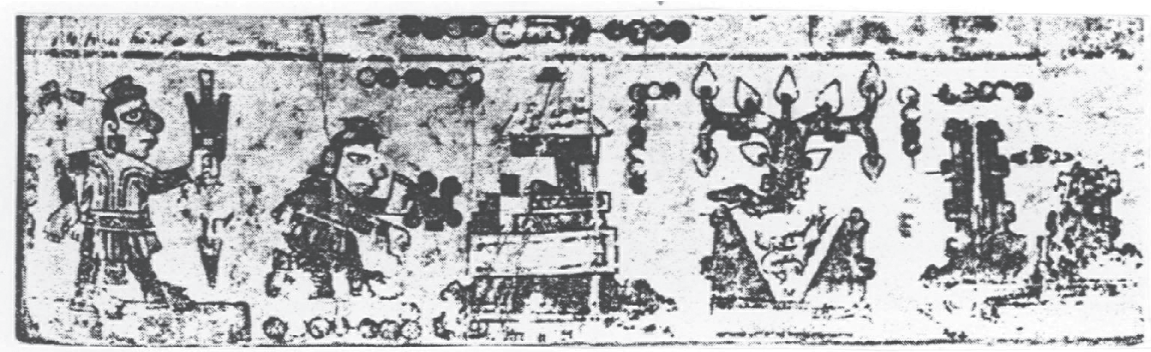

Figura 27. Códice Colombino, 4-III.

En la página 5 del Colombino encontramos a 8-Venado ya entronizado como señor de Tututepec y, justamente a la entrada del templo, nuevamente volvemos a encontrar juntos al Bastón Cosmológico y al bulto sagrado como señales de que se ha fundado ya un nuevo señorío (figura 28).

Encontramos otro contexto importante cuando el señor 8-Venado, después de su visita a Cholula, se traslada finalmente a Tilantongo para tomar posesión del señorío y fundar un nuevo linaje en el pueblo más importante de la Mixteca Alta. Precisamente al llegar a Tilantongo, 8-Venado coloca el Bastón Cosmológico a la entrada del Templo del Cielo junto con una flecha y el bulto sagrado, y enciende el fuego nuevo para después realizar rituales hacia los cuatro puntos cardinales y tomar posesión del señorío tal y como lo hizo en Tututepec (figura 29).

De esta manera, el acto ritual de fundación e inauguración de un nuevo linaje o de toma de posesión de un lugar se llevaba a cabo a través de una ceremonia con los símbolos sagrados, esto es: colocar el bulto sagrado dentro del templo

${ }^{16}$ Jansen, Huisi Tacu: Estudio interpretativo de un libro mixteco antiguo: Codex Vindobonensis Mexicanus I, p. 237. 


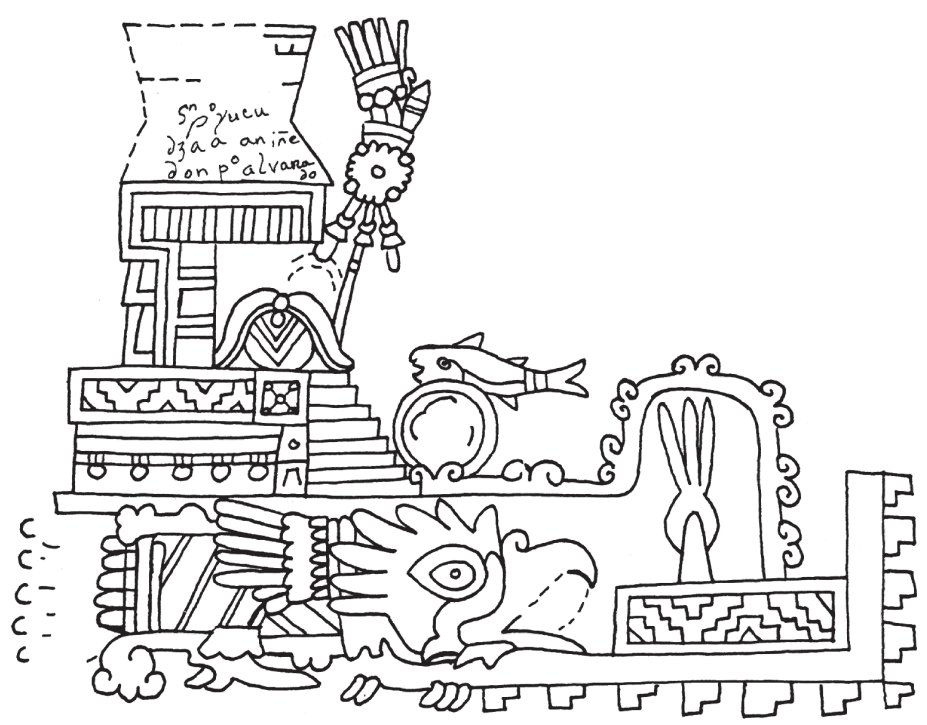

Figura 28. Códice Colombino, 5.

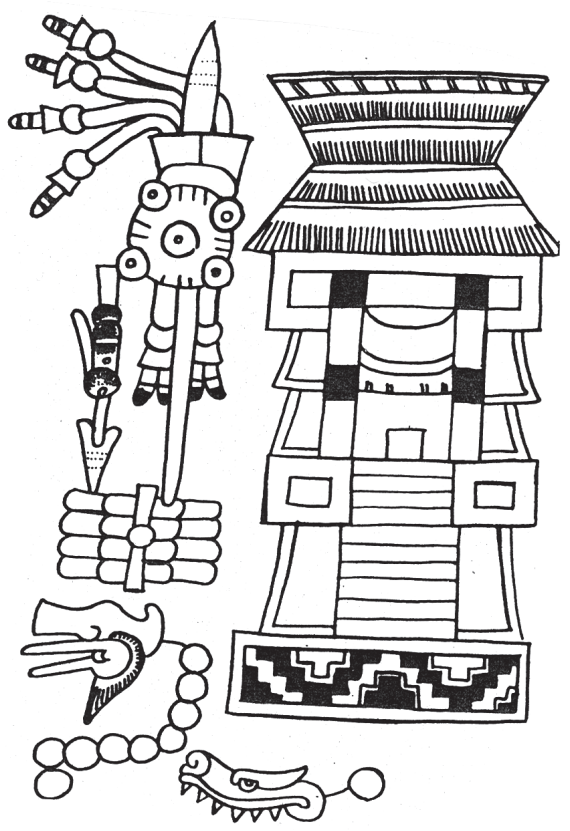

Figura 29. Códice NutTall, 53-IV. 
junto con el Bastón Cosmológico, encender el fuego ritual como símbolo de fundación y realizar ofrendas a los cuatro puntos cardinales en un acto simbólico para tomar posesión del sitio y de sus límites o confines sagrados. Por consiguiente, nos llaman la atención las similitudes existentes entre las escenas que vimos en el Códice Nuttall con la señora 3-Pedernal, por un lado, y los del señor 8-Venado por el otro; esto es, en ambos casos la fundación y toma de posesión de un lugar se realizaba por medio de ceremonias y rituales en los que estaban implicados los símbolos o instrumentos sagrados.

En conclusión, creo que a lo largo del presente artículo hemos logrado discernir el significado de un tipo de instrumentos imbuído de una gran significación religiosa, es decir, proponemos la existencia de algunos objetos manipulados por los gobernantes en espacios sagrados o en ámbitos rituales como son:

a) En fundaciones de pueblos o templos y en el establecimiento de linajes o dinastías por parte de los gobernantes. Este es el caso de los ejemplos analizados con el señor 8-Viento "Águila de Pedernales", fundador del pueblo de Suchixtlán; la fundación o establecimiento del culto a 9-Viento "Quetzalcóatl" a través del Templo de la Serpiente Emplumada; la inauguración de una nueva dinastía mediante el matrimonio de la señora 3-Pedernal (hija) con el señor 5-Flor; y las tomas de posesión y entronización por parte del señor 8-Venado en los señoríos de Tilantongo y Tututepec.

b) En las peregrinaciones hacia los puntos cardinales. Vimos este ejemplo cuando el señor 8-Venado recorre los sitios que simbolizan los cuatro rumbos del universo en el momento de tomar posesión de Tututepec y Tilantongo.

c) El bastón como objeto de culto. No descartamos la posibilidad de que el Bastón Cosmológico y el Bastón de Xipe fueran objetos de culto particular de los gobernantes. Vimos precisamente en el Códice Nuttall cómo dos importantes sacerdotes les rendían culto en el Templo de la Serpiente Emplumada por medio de un caracol y otros rituales de fuego. Gobernantes como 8-Venado probablemente hacían penitencias y sacrificios delante de los bastones del mismo modo como lo hacían ante los bultos sagrados.

Este culto a los bastones sagrados no es extraño en Mesoamérica, pues fray Bernardino de Sahagún en su Historia general nos dice sobre el culto y veneración que hacían los pochtecas a los báculos que usaban para caminar:

Todos los mercaderes usan desta manera de báculos por el camino, y cuando llegaban a donde habían de dormir, juntaban todos sus báculos en una gavilla atados, y hincábanlos a la cabecera donde habían de dormir, y derramaban sangre delante dellos, de las orejas o de la lengua o de las piernas o de los brazos. ${ }^{17}$

\footnotetext{
${ }^{17}$ Sahagún, Historia general de las cosas de Nueva España, lib. 1, cap. XIX, p. 56.
} 
Este autosacrificio a los báculos iba acompañado de ofrendas de copal y otras ceremonias para invocar su protección durante su viaje. Incluso, cuando ya regresaban de su travesía, nuevamente le rendían culto a los báculos:

Tenían que era imagen de aquel dios, [Yacatecuhtli] y que le había dado favor para ir y volver y andar los caminos que anduvo. Para hacer esta honra al báculo le ponían en una de las casas de oración que tenían en los barrios que ellos llamaban calpulli... En este calpulli donde se contaba este mercader ponían el báculo en lugar venerable. Y cuando daban comida a los convidados, primeramente ponían comida y flores y acáyietl, etcétera, delante del báculo. ${ }^{18}$

De esta manera, es probable que entre los mixtecos el culto al Bastón Cosmológico haya implicado también un culto a Quetzalcóatl, pues fue un símbolo traído por él desde el cielo hasta la tierra.

A diferencia de los bastones sagrados, pensamos que los objetos identificados como "cetros" suelen aparecer en contextos genealógicos y eran empleados únicamente por los gobernantes en situaciones específicas; por ello existe una clara distinción entre este tipo de instrumentos y los bastones sagrados tratados anteriormente. Desde luego, esto no quiere decir que tales cetros no hayan tenido un carácter sacro en la cultura mixteca, pero sí podemos diferenciarlos de los bastones sagrados. El Bastón Cosmológico no aparece implicado en las alianzas políticas de los gobernantes, ni los señores se representan portando los bastones en alguna junta o reunión; cuando se representa a la pareja gobernante, ésta no se aprecia nunca con el Bastón Cosmológico, pues seguramente éste permanecía en el templo y no en el palacio (los casos del Templo de la Serpiente Emplumada y los Templos del Cielo de Tilantongo y Tututepec con sus respectivos bastones son una prueba de ello). Los bastones son siempre cargados por dioses, seres semidivinos, sacerdotes y, en casos muy especiales, por señores o hijos de gobernantes que seguramente tenían la función de encargarse de su culto. Todo ello nos indica, sin duda, el significado y empleo de los bordones sagrados en la cultura mixteca.

\section{BIBLIOGRAFÍA}

Acuña, René (ed.)

1984 Relaciones Geográficas del siglo XVI: Antequera. México: UNAM, Instituto de Investigaciones Antropológicas. 2 vols.

1985 Relaciones Geográficas del siglo XVI: México. México, UNAM, Instituto de Investigaciones Antropológicas. 3 vols.

${ }^{18}$ Ibid., lib. 9, cap. III, pp. 57 y 58. 
Alvarado, Francisco de, fray

1962 Vocabulario en lengua mixteca, reproducción facsimilar con un estudio de Wigberto Jiménez Moreno. México: Instituto Nacional Indigenista, INAH.

Anders, Ferdinand, Maarten Jansen y Gabina Aurora Pérez

1992 Crónica Mixteca: el rey 8 Venado Garra de Jaguar y la dinastía de TeozacoalcoZaachila. Libro explicativo del llamado Códice Zouche-Nuttall. España, Austria, México: Sociedad Estatal Quinto Centenario, Akademische Druck-und Verlagsanstalt, FCE (Códices Mexicanos, II).

Arana, Evangelina y Mauricio Swadesh

1965 Los elementos del mixteco antiguo. México: Instituto Nacional Indigenista, INAH.

Byland, Bruce E. y John M. D. Pohl

1994 In the realm of 8 Deer: The archaeology of the Mixtec Codices. Norman, Londres: University of Oklahoma Press.

Caso, Alfonso

1960 Interpretación del Códice Bodley 2858. México: Sociedad Mexicana de Antropología.

1964 Interpretación del Códice Selden 3135 (A. 2). México: Sociedad Mexicana de Antropología.

1966 Interpretación del Códice Colombino y las glosas del Códice Colombino por Mary Elizabeht Smith. México: Sociedad Mexicana de Antropología.

1977 Reyes y reinos de la mixteca. México: FCE. 2 vols.

Códice Azcatitlan

1995 Introducción de Michel Graulich y comentario de Robert H. Barlow revisado por Michel Graulich. París: Bibliothéque Nationale de France-Société des Americanistes. 2 vols.

Códice Borbónico. Libro del Ciuacoatl. Homenaje para el año del Fuego Nuevo

1991 Introducción y explicación de Ferdinad Anders, Maarten Jansen y Luis Reyes García. España, Austria, México: Sociedad Estatal Quinto Centenario, Akademische Druck-und Verlagsanstalt, FCE.

Códice Borgia

1980 Comentarios al Códice Borgia por Eduard Seler. México: FCE. 3 vols.

Códice Florentino

1979 Edición facsimilar. México: Secretaría de Gobernación, Archivo General de la Nación. 3 vols.

Códice García Granados

1992 Estudio e interpretación de Xavier Noguez. México: Gobierno del Estado de México, El Colegio Mexiquense. 
Codex Vindobonensis Mexicanus 1

1974 Vollständige faksimile-ausgabe im original format. Graz: Akademische Druck-und Verlagsanstalt.

Coggins, Clemency

1988 "The Manikin Scepter: Emblem of Lineage”, Estudios de Cultura Maya, XVII: 123-158. México: UNAM, IIFL, Centro de Estudios Mayas.

De la Garza, Mercedes

1995 Aves sagradas de los mayas. México: UNAM, IIFL, Centro de Estudios Mayas.

1998 El universo sagrado de la serpiente entre los mayas. 3ª. reimpresión. México: UNAM.

2002 "El puesto del gobernante en el cosmos y sus ritos de poder", Estudios de Cultura Maya, XXII: 247-259. México: UNAM, IIFL, Centro de Estudios Mayas.

Durán, Diego de, fray

2002 Historia de las Indias de Nueva España e Islas de Tierra Firme, estudio preliminar de Rosa Camelo y José Rubén Romero. México: CONACULTA (Cien de México). 2 tomos.

Jansen, Maarten

1980 Tnuhu niquidza yya. Temas principales de la historiografía mixteca. Oaxaca: Gobierno del Estado de Oaxaca.

1982 Huisi Tacu: estudio interpretativo de un libro mixteco antiguo: Codex Vindobonensis Mexicanus I. Amsterdam: Centro de Estudios y Documentación Lationamericanos (Incidentele Publicaties, 24).

1997 "Símbolos de poder en el México antiguo", Anales del Museo de América, 5: 73-101. Madrid: Museo de América.

Jansen, Marteen y Gabina Aurora Pérez Jiménez

2000 La dinastía de Añute. Historia, literatura e ideología de un reino mixteco. Leiden: Research School CNWS.

Reyes, Antonio de los, fray

1976 Arte en lengua mixteca, edición facsimilar de la obra publicada en 1593. Nashville: Vanderbilt University.

Sahagún, Bernardino de, fray

2002 Historia general de las cosas de Nueva España, estudio introductorio, paleografía, glosario y notas de Alfredo López-Austin y Josefina García Quintana, $3^{\text {a }}$. ed. México: CONACULTA (Cien de México). 3 vols.

Smith, Mary Elizabeth

1973 Picture writing from Ancient Southern Mexico. Mixtec place signs and Maps. Norman: University of Oklahoma Press. 
Spores, Ronald

1984 The Mixtecs in ancient and colonial times. Norman: University of Oklahoma Press.

Torquemada, Juan de, fray

1975 Los veinte y un libros rituales y Monarquía Indiana, edición preparada por Miguel León-Portilla, $3^{a}$. ed. México: UNAM. 7 vols.

Troike, Nancy P.

1974 "The Codex Colombino-Becker". Disertación para obtener el grado de P.H.D., Londres: University of London. 